\title{
Ultraviolet index estimated in Badajoz (Spain) using a multiband radiometer
}

\section{Índice ultravioleta estimado en Badajoz (España) mediante radiómetro multibanda}

\author{
A. A. Piedehierro(1,*), J. A. Bogeat(1), M. L. Cancillo(1), A. Serrano(1), \\ G. Sánchez(1), M. Rodríguez-Arias(2) \\ 1. Department of Physics, University of Extremadura, Spain. \\ 2. Department of Mathematics, University of Extremadura, Spain. \\ (*) Email: piedehierro@unex.es \\ Recibido / Received: 30/01/2011. Aceptado / Accepted: 30/08/2011.
}

\begin{abstract}
:
The Ultraviolet Index (UVI) obtained by a multichannel radiometer GUV-2511 (Biospherical Instruments Inc.) is analyzed in this paper. This instrument has been recently installed in the radiometric station of Extremadura University in Badajoz (Spain). The UV Index has been calculated by a linear combination of three and four GUV channel irradiance values. In order to test these results, simultaneous values of UVI were calculated with the data provided by a well calibrated broadband UVS-E-T instrument co-located side by side the GUV multichannel. This radiometer has a spectral response that is adapted to the erythemal (sunburn) action spectrum of the human skin. One-minute simultaneous values of both instruments have been used to calculate ultraviolet Index (UVI). Although the measurement period is limited, it covers all sky conditions, from cloud-free to overcast days. UVI calculated with the whole data set by both methods are well correlated, but not as well as using only clear day data. It was observed that GUV underestimates UVI values (mean bias error, $\mathrm{MBE}=-18.9 \%$ ), being the four channel method the most successful.
\end{abstract}

Keywords: UV Radiation, Multichannel Radiometer, UV Index.

\section{RESUMEN:}

Se han analizado los primeros resultados del Índice Ultravioleta (UVI) obtenidos mediante un radiómetro multicanal GUV-2511 (Biospherical Instruments Inc.) instalado recientemente en la estación radiométrica de la Universidad de Extremadura en Badajoz (España). Mediante combinación lineal de las medidas de irradiancia de tres o cuatro canales del radiómetro multibanda se puede estimar el Índice Ultravioleta. Dichos resultados se han comparado con los valores simultáneos del UVI calculados a partir de medidas de un radiómetro de banda ancha UVS-E-T bien calibrado, cuya respuesta espectral está adaptada al espectro de acción eritemática de la piel humana. El estudio se ha realizado con datos promedio minutarios de un periodo de diez días en abril de 2010, cubriendo gran variedad de situaciones de cielo. Se ha obtenido una buena correlación entre los valores del UVI calculados por ambos métodos, sin embargo se observa que el radiómetro multicanal subestima los valores del índice ultravioleta para todos los casos, resultando un valor del estadístico MBE negativo, de $-18.9 \%$, siendo el método de cuatro canales el que proporciona resultados más próximos al instrumento de referencia.

Palabras clave: Radiación UV, Radiómetro Multicanal, Índice Ultravioleta. 


\section{REFERENCIAS Y ENLACES / REFERENCES AND LINKS}

[1]. A. F. McKinlay, B. L. Diffey, "A reference action spectrum for ultraviolet induced erythema in human skin", CIE Journal 6, 17-22 (1987).

[2]. World Meteorological Organization (WMO), Report of the WMO-WHO meeting of experts on standardization of UV indices and their dissemination to the public, Les Diablerets, Switzerland, 2124 July 1997, Tech. Rep. 127, WMO/Global Atmosphere Watch, Geneva, Switzerland (1998).

[3]. A. Dahlback, "Measurements of biologically effective UV doses, total ozone abundances, and cloud effects with multichannel, moderate bandwidth filter instruments", Appl. Opt. 35, 6514-6521 (1996).

[4]. M. Antón, Modelos Empíricos para la Estimación de la Irradiancia Solar Ultravioleta, Ph.D. Thesis, University of Extremadura, Badajoz, Spain (2007).

[5]. M. L. Cancillo, A. Serrano, M. Antón, J. A. García, J. M. Vilaplana, "Improving the solar zenith angle dependence of broadband UV radiometers calibration", Atmos. Chem. Phys. Discuss. 7, 17873-17892, (2007).

[6]. GUV-2511 User's Manual. Biospherical Instruments Inc. (2005)

\section{Introduction}

Solar ultraviolet radiation has significant adverse effects on human health such as skin diseases (erythema, photoaging, skin cancer, etc), cataracts, immune system effects, etc. The erythema (sunburn) is one of the negative effects of UV radiation most studied and it is calculated by weighting the solar UV radiation by the erythemal action spectrum CIE-1987, adopted by the "Commission Internationale de l'Eclairage" in 1987 [1].

All this highlights the need to alert the public about the risks of overexposure to UV radiation. To this end, several international organizations adopted the Ultraviolet Index (UVI) [2] that can be calculated from ultraviolet erythemal radiation (UVER). It is therefore essential determining the UV Index values in as many places as possible.

The most common way of measuring ultraviolet erythemal radiation is by using broadband radiometers that provide useful information, however, they do not permit distinguish between variations in ultraviolet radiation caused by changes in the total ozone amount from those due to cloud cover modification [3]. The multichannel radiometers are instruments that could complete this information allowing for ultraviolet radiation measurements in several spectral bands. Moreover, they can be used to estimate not only the erythemal radiation but also ozone and cloud transmission.
This study presents the first ultraviolet erythemal radiation measurements obtained by a GUV-2511 multichannel radiometer in Badajoz. Based on the method of Dahlback [3], UV Index has been calculated by a linear combination of irradiances provided by different channels. Sets of three and four wavelengths have been used for this purpose. Additionally, these UVI values have been compared with those obtained by a well calibrated UVS-E-T broadband radiometer, located side by side with GUV-2511 multichannel.

\section{Site description and instrumentation}

The data set used for this study has been collected in a radiometric station in Badajoz (Spain). It is located on the terrace of the Department of Physics building $\left(38.88^{\circ} \mathrm{N}\right.$, $7.00^{\circ} \mathrm{W}$ ). This station belongs to the AIRE Research Group of the Extremadura University.

A GUV-2511 multichannel radiometer (Biospherical Instruments Inc.) and a UVS-E-T broadband radiometer (Kipp \& Zonen) have been used. The UVS-E-T broadband radiometer measures in the spectral range between $280 \mathrm{~nm}$ and $400 \mathrm{~nm}$ and its spectral response is close to the CIE erythemal action spectrum. This instrument has a good angular response with deviation from the ideal cosine function less than $4 \%$ from $0^{\circ}$ to $70^{\circ}$. The radiometer is thermoelectrically stabilized at a temperature of $25^{\circ} \mathrm{C}$ and a desiccant cartridge keeps the interior dry. The UVS-E-T output voltages were sampled 
every ten seconds and recorded as one minute average on a CR1000 data acquisition system from Campbell Sci. and then are sent to a personal computer every twenty minutes.

In order to convert the voltages to ultraviolet erythemal irradiance (UVER), calibration factors were applied. These factors were obtained at National Institute for Aerospace Technology Laboratory (INTA, El Arenosillo, Huelva). The well-characterized spectroradiometer Brewer MK-III \#150 was used as the reference instrument.

The GUV-2511 multichannel radiometer consists of a sensor head and a control unit (deckbox). The sensor head is covered by a teflon diffuser and includes a set of six filters and detectors that permits to measure ultraviolet irradiances with moderate bandwidth of approximately $10 \mathrm{~nm}$ FWHM, centered at 305 , $313,320,340,380$ and $395 \mathrm{~nm}$, with $7.2 \times 10^{-7}$, $-1.6 \times 10^{-7}, \quad-2.8 \times 10^{-7}, \quad 1.6 \times 10^{-7}, \quad 6.6 \times 10^{-7}$, $-7.2 \times 10^{-8} \mathrm{~W} / \mathrm{m}^{2} \mathrm{~nm}$ as channel offset values. Its angular response has a deviation from the ideal cosine of $0-5 \%$ from $0^{\circ}$ to $70^{\circ}$ and $\pm 10 \%$ from $71^{\circ}$ to $85^{\circ}$. A seventh channel measures photosynthetically active radiation (PAR) between $400 \mathrm{~nm}$ and $700 \mathrm{~nm}$. A heat blanket maintains the diodes and filters at $40^{\circ} \mathrm{C}$. Binary data are transmitted from a microprocessorbased data acquisition system to the personal computer using a RS232 connection. The software provided permits to select the input channels as well as the sampling rate.

\section{Measurements and methods}

The measurements were taken with both instruments described above for a ten days period, from April 10 to 20, 2010. The GUV2511's output data have been averaged every minute to make them match up the data registered by the UVS-E-T radiometer. The calibration method used to determine the integrated erythemal irradiance by UVS-E-T broadband radiometer accounts for the zenith angle dependence as described in $[4,5]$. The UV index was therefore obtained from the integrated erythemal irradiance (in $\mathrm{W} / \mathrm{m}^{2}$ ) multiplied by a factor 40 , according to the joint recommendations of several international organizations [2].

The irradiance values recorded by the GUV2511 instrument for each channel have been determined by the direct use of the manufacturer calibration through the data acquisition software. Therefore, the ultraviolet index has been estimated every minute by a linear combination of the 305,320 and $340 \mathrm{~nm}$ channels, following Dahlback method [3] and using coefficients provided by Biospherical Instruments Inc.:

$$
\begin{aligned}
U V I_{3 C H A N N E L}= & 0.8911 E_{305}+0.0818 E_{320} \\
& +0.007751 E_{340} .
\end{aligned}
$$

In addition, a second method of estimation has been tested including a fourth channel centred in $313 \mathrm{~nm}$. The coefficients used were provided by Biospherical Instruments Inc. (Michael Holas, personal communication):

$$
\begin{aligned}
U V I_{4 C H A N N E L}= & 0 \\
& +0058 E_{305}+0.0887 E_{313} \\
& +0.0324 E_{320} \\
& +0.0131 E_{340} .
\end{aligned}
$$

To analyse the results, the mean absolute bias error $(M A B E)$, the mean bias error $(M B E)$ and the relative root mean square error (RMSEr) have been used. While the $M B E$ indicates whether the estimation of the UVI by the multichannel overestimates (positive values of $M B E$ ) or underestimates on average the reference value provided by the broadband radiometer, $M A B E$ statistic reports on the degree of fit between the two data sets. On the other hand, the RMSEr represents the relative average error.

$$
\begin{aligned}
M B E & =\frac{1}{N} \sum_{i=1}^{N} \frac{U V I_{G U V}-U V I_{U V S-E-T}}{U V I_{U V S-E-T}} \\
M A B E & =\frac{1}{N} \sum_{i=1}^{N} \frac{\left|U V I_{G U V}-U V I_{U V S-E-T}\right|}{U V I_{U V S-E-T}} \\
R M S E r & =\sqrt{\frac{1}{N} \sum_{i=1}^{N}\left(\frac{U V I_{G U V}-U V I_{U V S-E-T}}{U V I_{U V S-E-T}}\right)^{2}} .
\end{aligned}
$$

\section{Results}

According to the multichannel manufacturer specifications [6], only measurements 
corresponding to zenith angles under $60^{\circ}$ have been considered. In a first step, the whole oneminute data set has been used for this study but also two particular cases have been analyzed: a clear day (April 10 th 2010) and a cloudy day (April 14th 2010). The values of $M A B E, M B E$ and $R M S E r$ statistics resulting from the comparison between GUV and UVS-E-T ultraviolet index estimations are shown in Table I. The UVI values obtained using three and four channels of GUV multiband radiometer are presented for the three data sets considered (all data, clear and cloudy days). $N$ represents the number of data pairs used in the calculation.

These results show that both methods underestimate every one of the values given by the UVS-ET, for the three datasets, as deduced from the same absolute value of $M B E$ and $M A B E$. Regardless of the method for determining the UVI, better estimations are obtained in the absence of cloud cover. On the other hand, fourchannel method results are the closest to the reference values of the broadband radiometer, underestimating to a lesser extent the ultraviolet index.

TABLE I

$M A B E, M B E$ and $R M S E r$ statistics for estimations obtained using three and four channels.

\begin{tabular}{|c|c|c|c|c|}
\cline { 3 - 5 } \multicolumn{1}{c|}{} & $\begin{array}{c}\text { Whole } \\
\text { period }\end{array}$ & $\begin{array}{c}\text { Clear } \\
\text { day }\end{array}$ & $\begin{array}{c}\text { Cloudy } \\
\text { day }\end{array}$ \\
\cline { 2 - 5 } \multicolumn{1}{c|}{} & $N$ & 4979 & 460 & 470 \\
\hline \multirow{3}{*}{ channel } & $M A B E$ & $20.7 \%$ & $11.6 \%$ & $25.1 \%$ \\
& $M B E$ & $-20.7 \%$ & $-11.6 \%$ & $-25.1 \%$ \\
& $R M S E r$ & $21.7 \%$ & $11.9 \%$ & $25.3 \%$ \\
\hline \multirow{4}{*}{ channel } & $M A B E$ & $18.9 \%$ & $9.2 \%$ & $23.8 \%$ \\
& $M B E$ & $-18.9 \%$ & $-9.2 \%$ & $-23.8 \%$ \\
& $R M S E r$ & $20.1 \%$ & $9.8 \%$ & $24.0 \%$ \\
\hline
\end{tabular}

The temporal evolution of the UVI estimations for the clear and overcast days selected can be seen in Figs. 1 and 2. According to the results of Table I, these graphics show that the method of four channels (red line) is the closest to the UVS-E-T reference radiometer (black line), behavior that stands out in Fig. 1. Although this trend is maintained regardless of sky coverage, MBE difference between the two methods is more pronounced in the case of clear day. That is, under these circumstances, the application of four-channel method introduces a significant improvement in the UVI estimation.

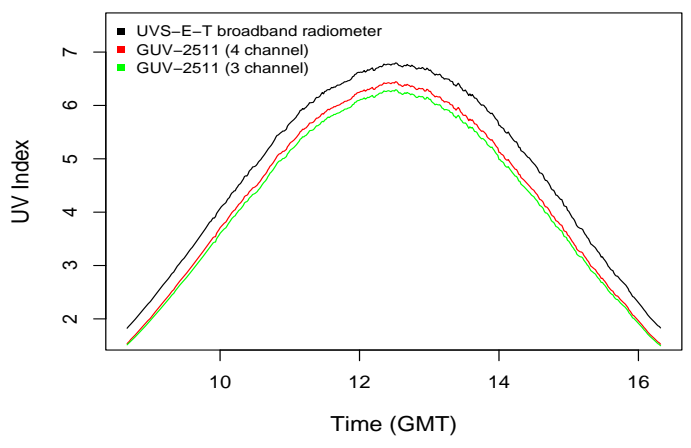

Fig. 1. UVI estimation by 3 and 4 channel method for a clear day (April 10 th 2010 ).

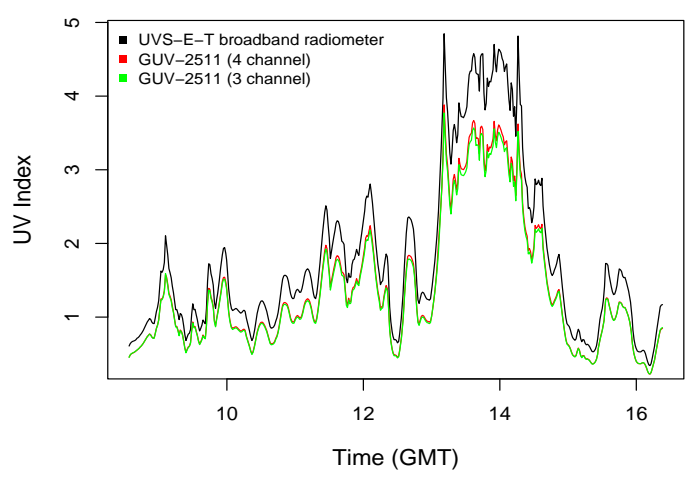

Fig. 2. UVI estimation by 3 and 4 channel method for a cloudy day (April 14th 2010$)$.

\section{Conclusions}

The first results of UV Index obtained by GUV2511 instrument have been satisfactory. This study reveals that both calculation methods systematically underestimate the UVI, however, for clear sky conditions (MBE 3 CHANNEL $=$ $\left.-11.6 \%, M B E_{4 C H A N N E L}=-9.2 \%\right)$, UVI estimations are considerably closer to the expected reference values. The results for overcast days are not very encouraging $\left(M B E_{3 C H A N N E L}=\right.$ $\left.-25.1 \%, M B E_{4 C H A N N E L}=-23.8 \%\right)$, so for the current configuration of the instrument, it is advisable to only consider the UVI obtained in clear sky days.

Considering the whole data set, the comparison between the method using three channels and the other one with four channels shows that the last one provides better estimates of UVI $(M B E=-18.9 \%)$. This 
improvement becomes more evident in situations without cloud cover.

The results suggest the need for a recalibration of the multichannel instrument using spectral information such as that provided by a spectroradiometer.

\section{Acknowledgements}

This work is partially supported by the research projects CGL2008-05939-C03-02/CLI, CTM2008 -03114-E and CGL2011-29921-C02-01 granted by the Spanish Ministerio de Ciencia e Innovación.

A. A. Piedehierro and J. A. Bogeat thank the Spanish Ministerio de Educación for their "Beca de Colaboración" and A. A. Piedehierro thanks the Junta de Extremadura for the FPI grant. Special thanks to Michael Holas from Biospherical Instruments Inc. for his valuable help. 